\title{
The views of key stakeholders on an evolving food risk governance framework: Results from a Delphi study
}

\author{
M.T.A. Wentholtt ${ }^{\mathrm{a}, *}$, G. Rowe ${ }^{\mathrm{b}}$, A. König ${ }^{\mathrm{c}}$, H.J.P. Marvin ${ }^{\mathrm{d}}$, L.J. Frewer ${ }^{\mathrm{a}}$ \\ a Marketing and Consumer Behaviour Group, Department of Social Sciences, Wageningen University, Hollandseweg 1, 6706 KN Wageningen, The Netherlands \\ ${ }^{\mathrm{b}}$ Institute of Food Research, Colney Lane, Norwich NR4 7UA, UK \\ ${ }^{c}$ Conseillère auprès du Recteur, Université du Luxembourg 162A, Avenue de la Faïencerie, L-1511 Luxembourg, Luxembourg \\ ${ }^{\mathrm{d}}$ RIKILT-Institute of Food Safety, Bornsesteeg 45, 6708 PD Wageningen, The Netherlands
}

\section{A R T I C L E I N F O}

Article history:

Received 19 August 2008

Received in revised form 22 May 2009

Accepted 12 June 2009

\section{Keywords:}

Food

Risk management

Risk communication

Risk analysis

Delphi

\begin{abstract}
A B S T R A C T
Evidence of a decline in public trust associated with food risk governance over recent years has called into question the appropriateness of the current dominant risk analysis framework. Within the EU-funded SAFE FOODS project a novel risk analysis framework has been developed that attempts to address potential shortcomings by increasing stakeholder (including consumer) input, improving transparency, and formally incorporating benefit and non-health aspects into the analysis. To assess the viability of this novel framework, the views of food risk experts from the EU and beyond were sought using a distributed online questionnaire process called Delphi. In this paper the main results of this survey are described, revealing varying levels of support for the key innovations of the novel framework. Implications of our results for the new and old frameworks, for the future of risk analysis, and for the policy community more widely, are discussed.
\end{abstract}

(c) 2009 Elsevier Ltd. All rights reserved.

\section{Introduction}

Food risk analysis is currently the responsibility and preserve of expert risk assessors and professional risk managers. However, recent years have seen a decline in public trust in risk governance, particularly in the food domain, related to a number of high-profile food crises (e.g., Houghton et al., 2008). Recognition of this decline has led to moves by national and international responsible bodies (such as the European Food Safety Authority, EFSA) to attempt to increase public confidence in the risk analysis process by (for example), improving the transparency of risk analysis practices through increasing stakeholder (including consumer) input into the decision-making process. The institutionalisation of these practises has, largely been on an ad hoc basis. The impact of increased transparency and enhanced stakeholder engagement on consumer confidence has yet to be systematically evaluated (see Rowe, 2007). Additionally, there are a number of other factors not currently incorporated within the formal food risk analysis process (which focuses on risk to human health) that arguably should be taken into account. These include environmental, social, economic, and ethical impacts. By implication, the term "impact" incorporates assessment of both risk and benefit, as both are possible outcomes of many potentially hazardous events. However, the current

\footnotetext{
* Corresponding author. Tel.: +31 74822 55/33 85; fax: +31 7484361 .

E-mail address: meike.wentholt@wur.nl (M.T.A. Wentholt).
}

risk analysis framework tends to focus on risks, excluding consideration of benefits. ${ }^{1}$

The Framework VI EU-funded SAFE FOODS project (2004-2008) has aimed to develop an improved risk governance framework for foods that explicitly incorporates stakeholder consultation, public participation, and risk-benefit assessment. In addition, the framework formally considers the question of whether to include assessments related to non-human health aspects, such as environmental, socio-economic and ethical impacts. Emphasis is placed on enhanced transparency throughout the process.

In this paper we describe how, in the course of developing the food risk analysis framework, expert opinion was sought through a specific iterative, distributed method. Following elaboration on the issue of risk analysis and the potential problems associated with the dominant contemporary framework, a more integrated risk analysis framework is presented. The problems of acquiring expert opinion on such an important issue are outlined. One particular approach for overcoming some of these difficulties, the Delphi

\footnotetext{
${ }^{1}$ Exceptions to this general approach can be identified. For example, the acceptability of sodium nitrate as a food preservative has been evaluated (Branen et al., 2002). Some risk assessors have concluded that the potential (but small) longterm risks of cancer from the formation of nitrosamines is outweighed by the antibacterial benefits of the use of the preservative. Similarly, the risks from some fungicides, such as the Ethylene bisdithiocarbamates, and their metabolite ethylenethiourea, have been discounted because of the presumed benefits of reduced food losses due to spoilage (Schneider and Dickert, 1993).
} 
technique, is described. The SAFE FOODS Delphi consultation process is then outlined, and selected results are presented. The views of interested actors and stakeholders regarding the advantages and disadvantages of the framework are provided, together with views on its further development, along with commentary on the usefulness and limitations of the Delphi research method.

\section{Food risk analysis: processes and problems}

The dominant framework of risk analysis applied in the agrifood sector (FAO/WHO, 1995) comprises of three components: food risk assessment, food risk management and food risk communication. Risk assessment focuses on the systematic and objective evaluation of all available information pertaining to foodborne hazards. Food risk management aims to optimise protection of public health by controlling risks effectively through the selection and implementation of appropriate measures. It is within the remit of risk managers to consider various legal, political, social and economic issues, such as risk acceptability and policies for risk mitigation activities, although these other issues are excluded from risk assessment (despite data being available that could potentially contribute to understanding the effects of a specific hazard on these factors). Risk communication is defined as the interactive exchange of information and opinions concerning risks and risk management activities between risk assessors, risk managers, consumers and other interested parties. Interaction occurs between all three components of the framework.

It is accepted that food control systems are highly unlikely to deliver a completely risk-free food supply (WHO, 2004). However, some observers have described the food chain in Western Europe as having been subject to a 'paradox of progress' (Fischer and Frewer, in press). Increasingly strict standards, quality controls and monitoring procedures have been applied within the agri-food sector. This has been perceived to correspond with an increasing number of food safety incidents, which have contributed to a reduction in consumer confidence in food safety (e.g., Berg, 2004; de Jonge et al., 2007; Eiser et al., 2002; Frewer et al., 1996; Houghton et al., 2008; Vos, 2004). Prominent examples include outbreaks of Escherichia coli in hamburgers (Tuttle et al., 1999), Salmonella in eggs and poultry (Guard-Petter, 2001; French et al., 2005), Listeria in pates and soft cheeses (Ramsaran et al., 1998), and accidental or deliberate contamination of the food chain or specific food products with toxic compounds, such as dioxin (Verbeke, 2001). The bovine spongiform encephalopathy (BSE) crisis can perhaps be singled out as the most important factor leading to revisions of food safety policy in recent years (Reilly, 1999; Smith et al., 1999). Concerns about emerging technologies applied to the agri-food sector (such as genetic modification of crops) have also resulted in problems with public confidence in food risk analysis (see, for example, Frewer et al., 2004).

Various efforts have consequently been made to bolster societal confidence in food risk analysis. It has been argued that public trust in food safety will be facilitated by the functional (and in some instances structural) separation of components in risk analysis, particularly risk management and risk assessment (Houghton et al., 2008). This approach has been adopted by various institutions with responsibility for food safety governance, including EFSA. The effect on consumer and stakeholder trust has, however, proven difficult to assess, other than in aggregate terms (for example, by comparing societal trust ratings in different food safety institutions).

Other approaches to increasing societal trust in risk analysis practices have stressed the need to develop effective risk communication strategies with consumers that explicitly address their information needs (Houghton et al., 2006; Millstone and Van Zwanenberg, 2000; Van Kleef et al., 2007), or propose greater stake- holder involvement (including of consumers) in the overall process or specific stages of food risk analysis (Dreyer et al., 2006; De Marchi and Ravetz, 1999). Greater inclusivity may reflect institutional changes developed to increase the transparency and openness of regulatory practices (Byrne, 2002; Dreyer et al., 2006). The institutionalisation of these various strategies have been rather ad hoc, and their success (e.g. in terms of increasing public trust) has only been evaluated informally, if at all (e.g., Rowe, 2007). How best to operationalise these strategies in the case of food safety requires further analysis.

There are, other potential limitations to the dominant risk analysis approach currently applied. Quality of Life parameters in risk assessment, and other legitimate factors, including societal and economic factors, tend not to be considered explicitly (Cope et al., in press) and have not been translated into current practice in food safety regulation. There is a more general trend in policy making within the European Commission and beyond concerning the systematic assessment of economic, social, environmental, health and ethical factors associated with monitoring provisions (Dreyer et al., in press). For example, in the area of health impact assessment, consumption of specific foods may have both a positive and a negative health effect. A case in point is provided by fish and seafood. Biomagnification of persistent toxicants in freshwater and marine food chains provides an important pathway for human exposure. At the same time, fish may also constitute an important source of omega three fatty acids, which provide health benefits (e.g., Gochfeld and Burger, 2005; Levenson and Axelrad, 2006). Thus, assessment of health risks and health benefits are both relevant to the governance process. Similarly, quality of life assessment can also be quantified from a risk-benefit perspective, taking into account impact on different population segments (de Blok et al., 2007). Analysis of cost-benefit issues can be made in the context of environmental, health, and safety regulation (see for example, Arrow et al., 1997). Arguments can be provided to support analysis of both ethical costs and benefits associated with particular courses of (lack of) action (Wilson, 2002).

Given the uncertainties associated with when and how to involve stakeholders, and effectively communicate with the public, the lack of institutionalised and evaluated processes for promoting transparency, and the potential for assessment to also include systematic identification of the benefits (as well as risks) associated with potential food hazards, an improved food risk analysis framework is desirable. The development of a risk analysis framework that addresses these limitations has been an objective of one particular EU-funded project, entitled SAFE FOODS.

\section{The SAFE FOODS framework}

One aim of the SAFE FOODS project was to develop a risk governance framework that explicitly incorporates stakeholder consultation and public participation at appropriate stages in the process. The framework formally addresses the question of whether to include risk-benefit assessments, including those relating to environmental and socio-economic impacts, as well as ethical issues, and process transparency is emphasised throughout. The intermediate SAFE FOODS framework is summarised in Fig. 1.

The integrated framework describes an iterative decision process with four stages: framing, risk-benefit assessment, evaluation, and risk management (König et al., submitted for publication). At the framing stage, interested parties, experts and officials with interests in risk evaluation and management work together to gain an initial shared understanding of the issue, objectives, and broad courses of regulatory action. Areas of general agreement and dissent are documented in order to provide the basis for planning future decisions. The assessment and terms of reference, and 


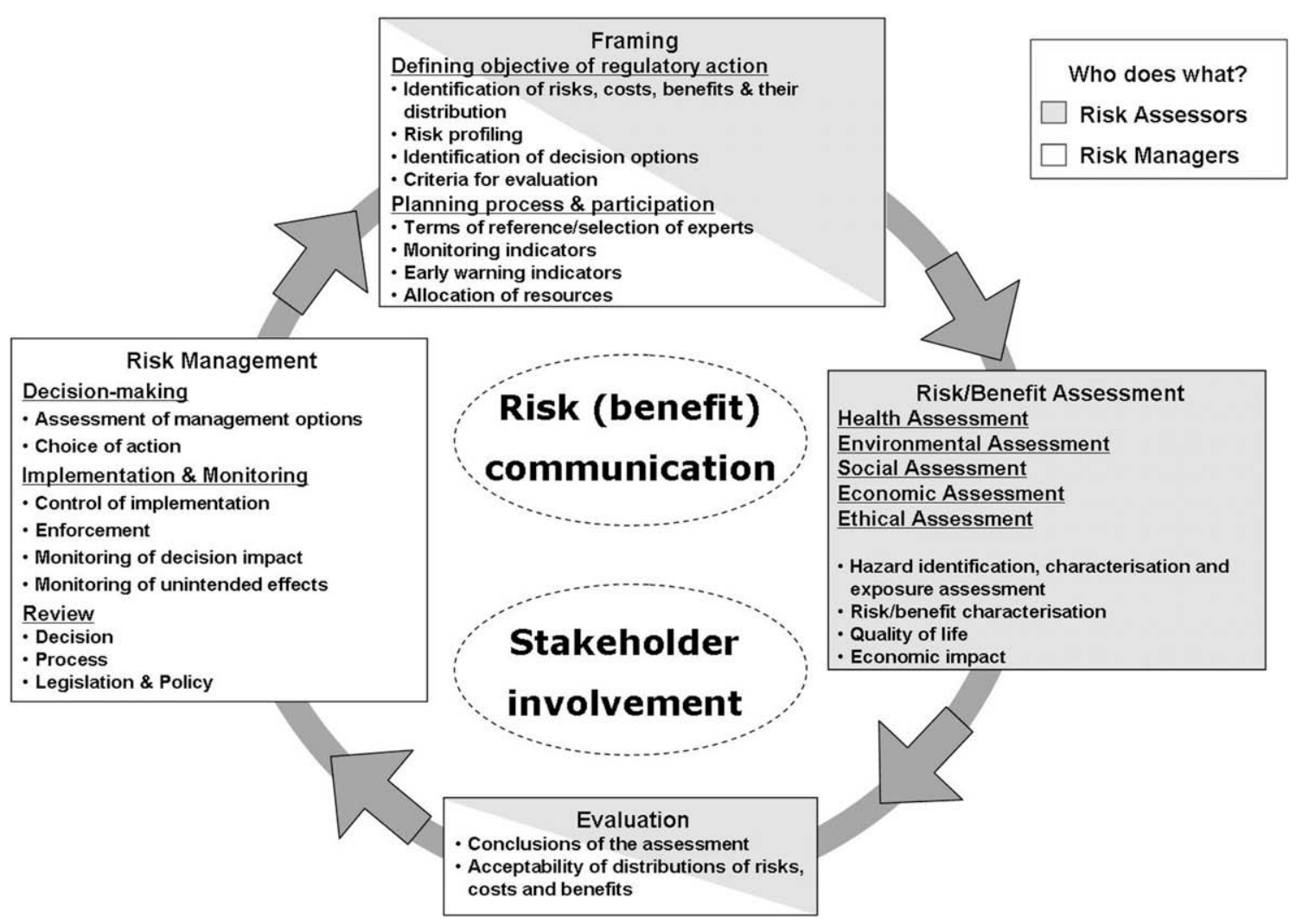

Fig. 1. The SAFE FOODS framework as used in the Delphi surveys.

proposed criteria for ranking regulatory options, monitoring indicators are included. The risk-benefit assessment pertains not only to single pre-identified risks, but to health impacts in general (including health benefits), as well as environmental, economic, social and ethical impacts, and their distribution. The evaluation stage is an intermediate stage between risk assessment and management, in which interested parties, experts and officials in risk assessment and management use the assessment outcome to compare the risks, costs, and benefits and their distribution, resulting in a report with recommendations on what consequences are deemed acceptable and what risk management measures may be required, from multiple perspectives. Risk management includes decision-making, implementation, monitoring and review, and involves the definition, ranking of alternative measures, and final selection of regulatory options, taking due account of assessment and evaluation activities. Monitoring indicators are defined based on proposals at the framing stage. Review pertains not only to the impacts of the decision itself, but also to the process by which the decision is made, and the legislation under which the issue is regulated.

The three main differences to current frameworks can be described as: (1) expansion of the scope of the formal risk assessment to include distributions of benefits and costs, (2) more formal (and institutionalised) stakeholder participation, and (3) improved risk communication and publicly accessible reports at each stage of the process. The draft framework has been put out for consultation with key actors and practitioners. Integrating practitioners in the development of the framework facilitates practicability and enhances the chances of adoption.

The remainder of this article deals with the problems of stakeholder consultation, and the description of one innovative method for understanding stakeholder views. Finally, what key participants think about the SAFE FOODS framework is discussed.
The problem of gaining expert opinion, and the Delphi technique as a solution

The SAFE FOODS framework is intended to have widespread applicability across many countries, with implications for many types of scientists, policy makers and other stakeholders. This raises the question of how it is possible to feasibly and validly consult with these diverse and significant constituencies in order to assess their opinions (given that their good opinions are crucial for the acceptance of the framework). One way to do this is to physically bring key stakeholders together to debate the framework - and this has, indeed, been done in the context of SAFE FOODS (see Walls et al., in press). However, this process has major practical constraints: it is both expensive and difficult to gather in one place at one time a significant number of relevant stakeholders.

Another way to consult multiple stakeholders is through a survey. For example, key stakeholders might be sent a description of the framework and asked their views on it. However, this approach does not allow for interaction and debate. Survey methodology is likely to reveal disparate opinions, but cannot offer the prospect of resolution of differing opinions.

A third technique, the Delphi method, involves a degree of interactivity and dialogue, as found in group meetings, allied to the practicability of a survey, with its benefits in terms of cost and potential access to wider expertise than might otherwise be attainable (Linstone and Turoff, 1975). The methodology essentially involves the repeated polling of diverse and distributed experts, the opinions from whom are used as feedback on subsequent 'rounds'. The Delphi method has been widely used to establish consensus regarding many different issues, often among experts (see, for example, Avery et al., 2005; Childs, 1998; Padel and Midmore, 2005), as well as to aid forecasting (Halal et al., 
1998). The technique has been successfully applied within the domain of food safety (Green et al., 1993; Henson, 1997; Medeiros et al., 2001; Menrad, 1999).

In the study presented here, 'panellists' (the experts/participants) were first sent a questionnaire about the SAFE FOODS framework, and then were presented with a second survey with similar questions, which they were asked to complete, reconsidering their views in the light of the opinions expressed by the other panellists on the first round.

There are a number of notable features about Delphi that need to be emphasized. First, the feedback provided is kept anonymous so that panellists do not know who said what, and are assured that their own opinions remain unattributed. This is a deliberate tactic to pre-empt the kind of social and political pressures that often emerge within groups, where decision quality can suffer as a consequence of, for example, people agreeing with authority figures so as to avoid sanction or gain some political advantage, or agreeing with majorities in order to appear part of a group rather than as a troublesome dissenter. Such processes are well documented and can lead to 'process loss' (inferior judgment and decision making compared to certain benchmarks, e.g., Steiner, 1972), and in extreme cases, to outcomes such as 'groupthink', which is the tendency for group members to try to minimize conflict and reach consensus without critically testing, analyzing, and evaluating ideas (e.g., Janis, 1972).

Second, the process aims to achieve a certain degree of consensus or at least general agreement, by collating panellists' opinions, with the average on the final round taken as the group's opinion. The final opinion is achieved by the equal weighting of all panellists' views. Again, in interacting groups, it may be that verbose or dogmatic individuals have differential input into the final decision - a bias that is not necessarily apt or beneficial. It is also important to note that consensus is not forced: the correct way to report the result of a Delphi process is to note the distribution of responses to indicate significant disagreements with the average view.

Third, there is considerable variation in how the Delphi method is implemented (Rowe and Wright, 2001). For example, there may or may not be an unstructured first round, in which the panellists are asked open questions about the nature of the topic of concern and the appropriateness of the proposed questions. The number of 'rounds' can also vary, though rarely goes beyond two or three. Delphi is also most often used to attain a quantitative representation of opinions - as in a numerical forecast or a prioritised list of options - though it can also be used for less-structured problems, where more emphasis is placed on qualitative arguments gained from iterated open questions. The nature of feedback often varies, usually comprising only the mean or median of panellists' responses to the prior round, but may also involve justifications from panellists for their judgments (Rowe and Wright, 2001).

Fourth, much is unknown about how Delphi 'works', i.e. the best way to apply it, with methodological variability largely stemming from practitioner uncertainty as opposed to being informed by empirical evidence of best practice - see Rowe and Wright (2001) for discussion. For example, regarding feedback, most published Delphi studies provide numerical averages of some sort, although feedback of rationales can lead to more opinion change than the use of statistics alone (e.g., Rowe and Wright, 1996). However, research into the application of Delphi has indicated most opinion change occurs following the first or second round, and that increased agreement (as measured by reduced variance of judgments) is a common feature of the process. There is evidence that the method does lead to improved judgmental quality when compared to interacting groups faced with the same task, and also when compared to the first round average of panellists' judgments (i.e. which would be achieved by averaging judgments from re- sponses to a survey) (Rowe and Wright, 1999). This suggests that Delphi not only provides a practical solution to the problem of gaining the opinions from distributed experts, but may lead to 'better' decisions or judgments. For these reasons, it was decided to run a Delphi process to assess participant views of the SAFE FOODS framework.

\section{Methods}

A two-round Delphi was conducted on an initial draft of the SAFE FOODS framework with all members of the project consortium. This allowed project members to have input into the design of the framework, and provided a pilot study of the Delphi process and questions. The framework was refined following the pilot study (see Fig. 1). The Delphi questionnaire was revised following the pilot in terms of number of questions, wording, and emphasis.

The Delphi method was actually applied to two sets of participants: the first comprised relevant participants from within the $\mathrm{EU}$; the second from outside the EU (here termed "International non-EU" participants). The participants were initially identified by a panel of SAFE FOODS project members on the basis of their personal knowledge of, and contacts with, key figures in the food safety domain. In the initial invitation letter, potential participants were informed that they would not be identified by name in any subsequent publications. Therefore, the Appendix contains a list of institutions to increase transparency of the study.

Two lists were developed, identifying an equal distribution of potential participants from four key constituencies: food risk managers, risk assessors, risk communicators (drawn from governmental institutes, academia and industry) and members of Non-Governmental Organisations (NGOs). Potential panellists received an Email invitation to take part in the Delphi, informing them of the purpose of the study and what it would involve.

The first round Delphi questionnaires were very similar for both sets of stakeholders (EU and International non-EU), with only a few differences in phrasing of the introduction text. The second round questionnaires, which were informed by the responses to the first rounds, diverged across the two stakeholder groups as different key issues emerged.

Whilst Delphi is often used to obtain quantitative responses to specific closed questions, the method has also been used to help elaborate policy through iterated open questions. The first round Delphi questionnaires thus comprised a combination of open and closed questions. Where closed questions were used - asking panellists specifically whether they agreed or not with some component of the SAFE FOODS process - panellists were also asked to explain their opinions. The second round questionnaire asked further questions on new issues that emerged from responses to previous open questions, plus iterated closed questions, and provided feedback on the opinions of panellists on the first round along with summaries of the written arguments given by panellists to justify their responses. Copies of each of the full versions of the questionnaires are available from the authors.

There were, in total, 36 questions in the first round. Four were related to the general framework, including questions about its comprehensiveness and structure; 16 questions asked about each of the four stages (four were about the framing stage, three about the risk assessment stage, two about the evaluation stage, and seven about the risk management stage); 16 questions dealt with a number of general features of the risk analysis concept, such as transparency and optimal stakeholder involvement. After approximately two weeks, panellists were sent E-mail reminders to complete the questionnaire if they had not already done so, repeated after another week. At approximately six weeks after the start of the process (for the EU participants - but 10 weeks for Interna- 
tional non-EU Delphi), participants were sent the second questionnaire, along with feedback from the first round (the numbers of participants are provided in Table 1). After the analysis of the first round, the qualitative questions were divided into those where general agreement of opinion arose or not. General agreement was defined as occurring when more than $75 \%$ of the participants agreed with a particular issue. A question would be again asked in the second round if no general agreement arose. Responses to open questions were analysed using Atlas.ti, a software package that facilitates textual content analysis. Based on the analysis new quantitative questions were developed for the second round.

The second questionnaire was shorter than the first, in terms of number of questions, but included considerable feedback text in the form of lists of panellists' justifications for their opinions and/or summaries of how panellists had responded (i.e. percentages of participants selecting each option). A number of new questions, based on responses to open questions, were asked to help the researchers understand panellist views. The questionnaire had fewer questions because those questions that had achieved very high first round agreement were not reiterated. In the Results section answers to a select number of the most interesting and relevant questions are discussed.

The methodology used in the International non-EU participant Delphi study was similar in process and design to that used in the EU-Delphi study. The first round questions were identical in both EU and International non-EU Delphi studies, but due to lower general agreement between the non-EU panellists the number of questions in the second round was slightly higher for this group. Furthermore, the second round questions for the latter focused more on a global, rather than EU, perspective. The Results section focuses on the levels of agreement and disagreement both within and between panellists in each of the EU and International nonEU participant groups.

\section{Results}

The most important results of the Delphi survey will be reported, in particular those directly relevant for the functioning of the SAFE FOODS framework, and those indicating disagreement between the EU and International non-EU participants.

\section{Sample characteristics}

Table 1 shows the number of potential participants identified for each Delphi panel within each constituency, as well as the number of actual participants who took part in the first and second rounds. As can be seen, approximately one-third of those invited took part in each of the two Delphi studies (i.e. the EU and International non-EU), and of these, approximately two-thirds responded to the second round questionnaires. These rates of attrition between rounds are typical of Delphi.

Participant characteristics are detailed in Table 2. There were more male participants than female (possibly reflecting a bias in the expert population). The majority of participants had more than 10 years' appropriate work experience, and their areas of expertise varied widely (see Table 2 , and note that participants could select more than one area of expertise). As well institutional affiliations of participants are provided in Table 2.

Table 1

Participants in the European and International non-EU Delphi studies.

\begin{tabular}{lcll}
\hline & Invited & Round 1 & Round 2 \\
\hline EU participants & 106 & $33(31 \%)$ & $21(64 \%)$ \\
International non-EU participants & 60 & $19(32 \%)$ & $12(63 \%)$ \\
\hline
\end{tabular}

Table 2

Characteristics of the expert panellists per Delphi survey round (\#).

\begin{tabular}{|c|c|c|c|c|c|}
\hline & & \multicolumn{2}{|l|}{ EU } & \multicolumn{2}{|c|}{$\begin{array}{l}\text { International } \\
\text { non-EU }\end{array}$} \\
\hline & & \# 1 & \# 2 & \# 1 & $\# 2$ \\
\hline \multirow[t]{2}{*}{ Gender $^{\mathrm{a}}$} & Male & 21 & 16 & 13 & 9 \\
\hline & Female & 12 & 5 & 4 & 3 \\
\hline \multirow[t]{4}{*}{ Work experience ${ }^{\mathrm{a}}$} & Less than 5 years & 1 & 0 & 1 & 1 \\
\hline & $5-10$ years & 8 & 4 & 1 & 1 \\
\hline & $10-20$ years & 9 & 9 & 3 & 1 \\
\hline & More than 20 years & 11 & 8 & 11 & 8 \\
\hline \multirow[t]{9}{*}{ Area of expertise $\mathrm{b}^{\mathrm{b}}$} & Policy making & 10 & 7 & 3 & 3 \\
\hline & Food & 19 & 13 & 9 & 9 \\
\hline & Health & 11 & 8 & 5 & 5 \\
\hline & Risk assessment & 9 & 6 & 8 & 8 \\
\hline & Risk management & 5 & 2 & 5 & 5 \\
\hline & Risk communication & 7 & 4 & 3 & 3 \\
\hline & Agriculture & 12 & 9 & 6 & 6 \\
\hline & Environment & 4 & 1 & 1 & 1 \\
\hline & Other ${ }^{\mathrm{c}}$ & 8 & 6 & 1 & 1 \\
\hline \multirow[t]{5}{*}{ Institutional affiliation } & Academics/scientists & 13 & 10 & 5 & 3 \\
\hline & Industry & 4 & 2 & 1 & 1 \\
\hline & $\begin{array}{l}\text { International governmental body } \\
\text { National governmental body }\end{array}$ & 4 & 2 & 8 & 4 \\
\hline & Non-governmental body & 4 & 3 & 4 & 3 \\
\hline & & 5 & 4 & 1 & 1 \\
\hline
\end{tabular}

\footnotetext{
a Not all participants filled in this question.

b Participants were permitted to respond to multiple categories to reflect their work activities.

c e.g. Economics; food safety; ethics; statistics/epidemiology; cell biology; biotechnology.
}

\section{The structure of the SAFE FOODS framework}

General agreement emerged regarding the need for change in the current processes of food risk analysis (EU: 78\% agreement, $22 \%$ disagreement; International non-EU: 94\% agreement, 6\% disagreement). Analysis of the qualitative responses to this question of both participant groups revealed views that factors other than health should be taken into account in risk assessment. Specifically assessment of benefits is important, and that better 'framing' of issues is needed. International non-EU participants were of the opinion that existing processes for crisis management are inadequate, and indicated that the communicative interface between risk assessors and risk managers needs to be improved. Following on from this, there was reasonable agreement regarding the proposed order of the four stages in the framework (EU: 84\% agreement, 6\% disagreement; International non-EU: 74\% agreement, 11\% disagreement). Further analysis of the qualitative responses indicated that the role of risk communication within the framework needs to be clarified.

Less agreement was found regarding the division of the stages. Participants agreed that there should be a clear distinction between the tasks conducted by risk assessors and risk managers, though not all agreed that there should be separate framing and evaluation stages:

"Although I agree that there should not be such a strict borderline between risk assessment and risk management, the three stages Framing, Risk/Benefit Assessment and Evaluation might [...] fall under the umbrella of risk assessment." [EU participant, round 1]

"Evaluation does not seem like a separate step - it is merely the conclusion of the risk-benefit assessment." [International nonEU participant, round 1]

However, some participants agreed that it is useful to have interface stages for risk assessors and risk managers to discuss the implications of risk assessments for their activities. 
"Stages where both risk assessors and managers are interactive are important and cannot be separated as shared planning is necessary and 'carry-through' of risk assessment to management is important.” [International non-EU participant, round 1]

\section{Communication with the public}

Both European and International non-EU participants agreed that uncertainties associated with risk assessment should be communicated to the public using simple and understandable language (EU: 90\% agreement, 3\% disagreement; International nonEU: $94 \%$ agreement, 0\% disagreement). Furthermore, there was consensus that this should be done in an open, honest, and transparent way.

Disagreement arose regarding what information should be communicated, and at which stages of the risk analysis process. Although European and International non-EU participants agreed in the first round of their respective Delphi surveys that communication is a priority at the risk management stage (EU: $88 \%$ agreement, 12\% disagreement; International non-EU: 90\% agreement, $0 \%$ disagreement), there was considerable disagreement as to what information should be communicated at other stages. For example:

"If we try to communicate all issues, we will dilute the messages and lose interest from the public - we need to have some sort of filter to decide what should be actively communicated and what should just be presented passively [...]." [International non-EU participant, round 1]

"There does not seem to be any clear reason why information should not be available at each stage." [EU participant, round 1] "The communication will make sense only when enough data are available, therefore, there is no need to do so in the first three stages." [International non-EU participant, round 1]

Some concerns were expressed that providing information about risk at too early a stage in the process would result in unnecessary alarm, or establish irreversible misconceptions:

"It might be too early to communicate on premature findings and incomplete risk assessments." [EU participant, round 1]

"Care should be taken not to alarm the public unnecessarily." [EU participant, round 2]

However, some participants indicated that uncertainty associated with some issues should not be communicated with the public.

"Communicating uncertainty in full and in a much too open way $[\cdots]$ could have a negative impact [on] [...] scientific new developments. It is important to pass the message that science is not black and white, evolves continuously and goes along with uncertainties." [EU participant, round 1]

"It is worse to be caught being less than complete, not open or honest or not transparent, than be understood wrongly. The first costs you your trustworthiness, the second only your efficiency." [EU participant, round 1]

"[The] public does not understand the scientific process, and definitely not uncertainty." [International non-EU participant, round 1]

\section{What type of data should be collected in the assessment stage?}

European participants were enthusiastic about collecting risk assessment data relating to environmental, social, economic and ethical impacts of potential food hazards, though there was less approval from International non-EU participants. Table 3 reveals that almost all participants agreed with the need to collect health impact data, as per current practice, while the majority of both EU and Inter- national non-EU participants thought that other types of data should also be collected. Interestingly, feedback of arguments on this issue in the second round led to a reduction in support for collection of the other types of data (except for environmental impact data with EU participants). By the second round, International nonEU participants who thought that social and economic data should be collected were reduced to a slight minority, while participants were evenly split concerning the collection of ethical impact data.

Participants from each group noted that, even if it is desirable to collect data in addition to health, there is a need to develop methodological innovations in order to so do.

"Methods for analyzing the first four types of impacts are fairly well-developed, although less so in the case of social impacts. However, this is not true for the last (ethical [impact]), so some specificity is required here." [International non-EU participant, round 1]

International non-EU participants indicated that, for some of the impact assessments, the issues are more relevant to the risk management stage:

"Full social and ethical issues will not become apparent until after the implementation of any new technology, process or product. They should be dealt with afterwards as a part of risk management [...]." [International non-EU participant, round 1] "I agree the social, economic and ethical aspect should be considered but only on a later stage. Otherwise the risk assessment might be compromised." [International non-EU participant, round 1]

It was unclear at the outset of the study as to whether participants would think it sensible to include consideration of benefits at the assessment stage. For this reason, round 1 of the survey simply asked: "Do you think that data on benefits should also be collected at this stage?" Among EU participants, 84\% agreed, 13\% neither agreed nor disagreed, and 3\% disagreed, while among the International non-EU participants, 79\% agreed, 5\% neither agreed nor disagreed, and $16 \%$ disagreed. The results indicated agreement with the use of such data, and so questions in round 2 (in both surveys) focused on participants' opinions regarding the use of the different types of benefits. These results suggested that there was less agreement between EU and International non-EU participants regarding whether or not data on benefits should be collected (Table 3). The majority of EU participants were in favour of collecting benefit data at the assessment stage (and were almost unanimous regarding the collection of health benefit data). International nonEU participants were far more equivocal. A small majority agreed with the collection of health benefit data, and participants were evenly split on whether environmental and economic data should

Table 3

Percentage of participants agreeing to the collection of different types of risk and benefit assessment data.

\begin{tabular}{llcll}
\hline Type of Impact & Participant & Round 1 $^{\mathrm{a}}$ & Round 2 & \\
\cline { 4 - 5 } & Stakeholder group & Risk data & Risk data & Benefit data \\
\hline Health impact $^{\mathrm{b}}$ & EU & 93 & 100 & 95 \\
& Non-Eu & 100 & 100 & 58 \\
Environmental impact & EU & 90 & 95 & 81 \\
& Non-Eu & 63 & 58 & 50 \\
Social impact & EU & 73 & 60 & 55 \\
Economic impact & Non-Eu & 53 & 42 & 33 \\
& EU & 80 & 71 & 67 \\
Ethical impact & Non-Eu & 63 & 42 & 50 \\
& EU & 76 & 68 & 61 \\
& Non-Eu & 58 & 50 & 42 \\
\hline
\end{tabular}

\footnotetext{
a Data on benefit assessment was only collected in the second round, based on responses of participants in the first round.

b Please note: the exact phrasing of the item regarding risks was: "health impact
} ("traditional' risk assessment)" and for benefits it was: "health impact". 
be collected. A slight majority disagreed that social and ethical data should be collected. Among the negative arguments presented by International non-EU participants were:

"Benefits are hard to quantify even for health aspects so it is not clear how this would be used." [International non-EU participant, round 1]

"One should not separate risk and benefit. Those who urge doing so are perhaps suspicious of industry propaganda, and there are good reasons in the past for such suspicions. The most important thing is that the trade-offs between risk and benefit must be analyzed very, very carefully. Also the distribution: those at risk, and those who benefit, can be very different." [International non-EU participant, round 2]

However, even supporters of the general concept (amongst both EU and International non-EU participants) expressed some uncertainty as to what benefit data should be acquired, when, and how:

"In some cases it may not be necessary, or it may be too difficult or legally not possible." [International non-EU participant, round 1]

"Benefits [...] [associated with] health and environment should be considered prior to benefits towards the other aspects [i.e. Social, economic and ethical]." [EU participant, round 1]

"It's clear from, for example, the GM debate that European consumers must benefit from a risk in order to accept it. Investigating and communicating benefits will help both policy development and public decision making." [EU participant, round 1]

"It may be difficult to collect benefit data across all areas from an early stage and in many cases it may not be necessary; it would be more efficient (resource wise for instance) to first evaluate benefit in the 1 or 2 most obvious areas and then widen..." [EU participant, round 1]

\section{What type of data should be collected in the evaluation stage?}

It was also interesting to assess participants' opinions on the use of non-health types of data in the evaluation stage of the framework. In the first round, participants were asked (in both surveys) to rank the relative importance of the different types of data (with ' 1 ' being most important). The Friedman rank test indicated that there was a significant difference between the rankings of International non-EU participants $\left(\chi^{2}(4, N=18)=40.6, p<0.001\right)$, but not between the rankings of the European participants $\left(\chi^{2}(4, N=28)=3.7\right.$, $p<0.4$ ). Post hoc comparisons (Wilcoxon signed rank test for two related samples) between the International non-EU participants' data reveals a significant difference between the health impact and all other impact factors $(p<0.001)$, indicating that health was ranked more important. The ranking of ethical impact versus social impact and economic impact were also significantly different (respectively, $p<0.01 ; p<0.05$ ), indicating that ethical impact was rated significantly lower than these factors. An overview of mean rankings of the impact factors can be found in Table 4 .

"From the consumer protection perspective health impacts are most important. But also social aspects (e.g., non-acceptance [of emerging technologies]) are from our perspective more important than environmental aspects." [EU participant, round 1] "All the factors should be weighed equally importantly in the evaluation... For example, any risk to health is always considered in relation to the financial and economic cost. This is of course different to specifying that a certain [protection from] risk has to be achieved no matter what the cost or other impacts. But this does not happen in reality." [EU participant, round 1]
Table 4

Mean ranking of priorities for different types of impact data (Delphi round 1, on a scale where rank 1 is most important).

\begin{tabular}{lll}
\hline & EU mean rank & Non-EU mean rank \\
\hline Health impact & 2.63 & $1.12^{\mathrm{a}}$ \\
Environmental impact & 2.82 & $3.24^{\mathrm{b}}$ \\
Social impact & 3.18 & $3.32^{\mathrm{c}}$ \\
Economic impact & 3.02 & $3.24^{\mathrm{b}}$ \\
Ethical impact & 3.36 & $4.09^{\mathrm{d}}$
\end{tabular}

Note: Means with the same subscript are not significantly different. Differences are significant at $p<0.05$.

Another issue that emerged for some is that consideration of factors in addition to health should be on a case-by-case basis.

"Health must be no. 1 - the food must be safe, i.e., meets the community's acceptable level of risk. The ranking of the other factors will depend on the nature of the issue - in most cases, not all will be relevant. .." [International non-EU participant, round 1]

Which stakeholders should be involved and at what stage of the risk analysis process?

Analysis of qualitative responses indicated that participants generally agreed that the most important aspect concerning stakeholder involvement within risk analysis is that involvement be "case-by-case". Specifically, the types of expertise needed and the extent and nature of stakeholder involvement will be dependent on the potential hazard under consideration:

"Stakeholder involvement will depend on the issue and whether they have relevant data and expertise." [International non-EU participant, round 1]

In the first rounds of both the EU and the International non-EU Delphi, participants were asked which stakeholders should be involved in which stages. The results are summarised in Tables 5a and 5b. European participants were in favour of involvement of all stakeholders, including the general public, at the framing stage. A similar pattern was observed for the International non-EU stakeholders, with the exception regarding the involvement of the general public or other NGOs. Both European and International nonEU stakeholders agreed that assessment should be the responsibility of regulatory institutions and scientific experts, and that the general public, farmers and other NGOs should be excluded from risk assessment.

"The assessment and decision making is properly the responsibility of public agencies. But they can only do their job if they

Table 5a

Which stakeholders should be involved in the risk analysis process at which stage? (EU participants, round 1).

\begin{tabular}{|c|c|c|c|c|}
\hline & \multicolumn{4}{|c|}{ Agreement with stakeholder input (\%) } \\
\hline & Framing & $\begin{array}{l}\text { Risk/benefit } \\
\text { assessment }\end{array}$ & Evaluation & $\begin{array}{l}\text { Risk } \\
\text { management }\end{array}$ \\
\hline $\begin{array}{l}\text { Regulatory } \\
\text { institutions }\end{array}$ & 75 & 61 & 75 & 82 \\
\hline Scientific institutions & 68 & 82 & 64 & 53 \\
\hline $\begin{array}{l}\text { Consumer } \\
\text { associations }\end{array}$ & 89 & 46 & 68 & 50 \\
\hline $\begin{array}{l}\text { Environmental } \\
\text { organisations }\end{array}$ & 79 & 54 & 71 & 57 \\
\hline Industry & 78 & 57 & 64 & 50 \\
\hline $\begin{array}{l}\text { Farmers } \\
\quad \text { (organisation) }\end{array}$ & 68 & 36 & 50 & 43 \\
\hline $\begin{array}{r}\text { Retailers, trade } \\
\text { organisation }\end{array}$ & 75 & 43 & 64 & 43 \\
\hline Other NGO & 64 & 29 & 43 & 32 \\
\hline General public & 71 & 25 & 46 & 39 \\
\hline
\end{tabular}


Table 5b

Which stakeholders should be involved in the risk analysis process at which stage? (International non-EU participants, round 1).

\begin{tabular}{lllll}
\hline & \multicolumn{3}{l}{ Agreement with stakeholder input (\%) } \\
\cline { 2 - 5 } & Framing & $\begin{array}{l}\text { Risk/benefit } \\
\text { assessment }\end{array}$ & Evaluation & $\begin{array}{l}\text { Risk } \\
\text { management }\end{array}$ \\
\hline $\begin{array}{l}\text { Regulatory } \\
\text { institutions }\end{array}$ & 100 & 75 & 88 & 94 \\
$\begin{array}{l}\text { Scientific institutions } \\
\begin{array}{l}\text { Consumer } \\
\quad \text { associations }\end{array}\end{array}$ & 81 & 94 & 75 & 69 \\
$\begin{array}{l}\text { Environmental } \\
\quad \text { organisations }\end{array}$ & 63 & 31 & 50 & 81 \\
$\begin{array}{l}\text { Industry } \\
\begin{array}{l}\text { Farmers } \\
\quad \text { (organisation) }\end{array}\end{array}$ & 75 & 44 & 44 & 56 \\
$\begin{array}{l}\text { Retailers, trade } \\
\quad \text { organisation }\end{array}$ & 63 & 25 & 50 & 75 \\
$\begin{array}{l}\text { Other NGO } \\
\text { General public }\end{array}$ & 56 & 12 & 50 & 75 \\
\hline
\end{tabular}

are well-informed, which includes listening carefully to stakeholders." [International non-EU participant, round 2]

The International non-EU participants suggested that other stakeholders could participate at a less "expert" level (for example, by collecting and delivering data to the expert communities with responsibility for assessment). European participants were undecided about the inclusion of the general public, farmers and "other NGOs" at the evaluation phase. In contrast, the International nonEU stakeholders emphasised the role of expertise in evaluation (regulatory bodies and scientists). Regarding risk management, European stakeholders favoured inclusion of regulatory institutions and exclusion of the general public and "other NGOs", whereas the International non-EU participants favoured a much broader range of stakeholder input into the risk management stage, and were only undecided about the inclusion of environmental NGOs in risk management.

"There should be a responsible group for risk management, and no diffusion of responsibility. In all other stages, a broad consultation process seems to be helpful." [EU participant, round 1] "If EFSA or some other part of the EC/EU or national government is equipped to do the entire risk analysis process, that group should do the major parts of the work. Other groups have some role to play in the "framing" stage, or in reporting risk information in the risk management stage." [International non-EU participant, round 2]

\section{Challenges for implementation of the SAFE FOODS framework}

As one participant put it:

“All new processes are a challenge..." [EU participant, round 1]

In an open question in the first round, participants were asked to state what they saw as the main challenges to the implementation of the SAFE FOODS framework. One concern voiced was that the framework would be time consuming and labour intensive to apply (with commensurate cost issues). It would thus be important to demonstrate that the framework could operate within an acceptable time frame before regulatory uptake could occur.

"Due to the involvement of more stakeholders/groups and more risk/benefit assessments the timing gets extended and planning is even more important." [EU participant, round 1]

"This type of framework moves towards a much more participatory process. Many individuals involved in regulation have little experience with working in such a manner. Another main chal- lenge will be striking a balance between having a framework and process that improves legitimacy, but that is still flexible and affordable." [EU participant, round 1]

Doubts were also raised as to whether the new framework could be operationalised to respond quickly and sufficiently if a food safety "crisis" were to occur. This is especially important given that a number of participants suggested that the framework is inappropriate for routine food risk analysis and established food hazards. Consequently there is a need to stipulate criteria for determining under what circumstances the new framework should be applied (identifying 'triggers'), and potential "candidate" hazards ought to be identified on a case-by-case basis.

"I do not see a "fast track" procedure for crises situations where actions have to be quick e.g. a screening group that remains on the alert at all times. Transparency is very important but could be time consuming." [International non-EU participant, round 1]

The European group was particularly concerned with problems relating to hazard identification, especially under conditions where the hazard is poorly characterised. It was recognised that, within the EU, a risk-benefit communication strategy would have to be developed that was appropriate to the needs of different EU member states and the "cultural diversity" encompassed with the EU structure.

Some participants suggested that the SAFE FOODS framework is not novel, and that similar approaches are being developed elsewhere:

"I do not think the SAFE FOODS risk analysis framework is that much different from frameworks promoted by Codex and other groups. The bigger challenge is where such risk analysis frameworks and (most importantly) some form of infrastructure that they need to be built on to make them effective is non-existent." [EU participant, round 1]

However, others (especially International non-EU participants) suggested that the framework is significantly different, but that in consequence this could cause problems on account of difficulties in harmonisation with existing International non-EU frameworks.

"It does not correspond to the Codex Risk analysis framework will be difficult for the 165 non-EU countries in the world to understand why EU needs a special framework different from everybody else's." [International non-EU participant, round 1]

In line with this, one participant suggested that the need to increase food safety resource allocations to operationalise the framework might also have an impact on European trading partners and developing countries if additional barriers to trade were identified.

\section{Discussion}

In this paper an improved risk analysis framework for use in the food domain has been described, along with the results of a major stakeholder consultation exercise about its perceived merits and deficits. The Delphi method used to enact this consultation was found to be an extremely useful mechanism in enabling the surveying of multiple experts from around the world who would not otherwise have been able to meet on a face-to-face basis. However, the complexity of the SAFE FOODS framework, and the number of questions that potentially could have been asked, suggest that there may have been value in having a third round of the survey to clarify views further (particularly as the first round contained many qualitative questions seeking to establish what the real issues really were). However, it was felt that this would have yielded diminishing returns, particularly in terms of expert partic- 
ipation. Two rounds seem ideal, though in future the method might benefit from an initial face-to-face qualitative stage (such as using a workshop with only a few experts) to clarify the major issues, which might then be focused on subsequently in a couple of largely quantitative Delphi rounds. The authors aim to look into developing such a novel method in future.

What was notable was that most of the novel concepts in the SAFE FOODS framework were acceptable to many of the experts, though EU experts seemed somewhat more positive, in general, than International non-EU experts. Thus, there was a certain support for the idea of including other aspects of risk than health in the assessment and analysis process, as well as including benefit information. There was general support for increasing the role of other stakeholders in the overall risk analysis process at specific points in the risk analysis process. One issue that arose was that the use of the different new elements proposed should be considered on a case-by-case basis. This, adds another level of complexity to the process, and perhaps needs to be explicitly considered within the framework - whether early on, or at particular stages.

This study has shown that the majority of the participants consulted in this study believe that implementing the proposed risk analysis framework amendments may result in better food risk governance and increased public trust in risk governance practices. At the same time, participants acknowledged that new tools and methods are needed to accommodate these improvements. Encouraging in this regard is the observation that governmental institutions have already started implementing various new elements as described in the SAFE FOODS framework. It is inevitable that implementation of improvements will take time and may differ in details between institutions. The outcome of the SAFE FOODS project may be helpful to identify those elements in risk analysis that will potentially benefit from international harmonisation.

\section{Conclusions}

There was considerable support for many of the new principles encompassed by the SAFE FOODS framework, but some uncertainty was expressed regarding how, in practice, these might be enacted. For example, there was some discussion regarding how stakeholders should be involved, the appropriate methodological approaches required to measure risks and benefits associated with the different impact factors (including health), and how these different factors should be weighted in the risk analysis process. The results from this survey raise further questions regarding the operationalisation of the framework, though they do suggest that it is worth persevering with. It would be naïve to expect that a 'better' framework will necessarily supplant one already institutionalised unless there is considerable stakeholder and end-user acceptance of the new approach. A final conclusion relates to the difference between stakeholder acceptance and institutional implementation and harmonisation in institutional application. It is also clear that a guidance is needed regarding when to do what (for example, in the framing phase stakeholders will profile the problem hence determine what activities are needed to solve the specific problem at hand). The issue of implementation lies, therefore, less with regulatory acceptance, but rather with operationalising specific institutional activities.

\section{Acknowledgements}

The research reported here was funded by the European Commission integrated project SAFEFOODS ("Promoting food safety through a new integrated risk analysis approach for foods"). The views expressed here are entirely those of the authors. We would particularly like to thank all participants for their time and effort to fill in the questionnaires. In addition we would like to thank Julie Houghton, Dr. Filip Cnudde, Dr. Ellen van Kleef, Heleen van Dijk and Shannon Cope for their comments and input, as well as Dr. Harry Kuiper (co-coordinator of the SAFE FOODS project).

\section{Appendix}

Institutional affiliations of participants in the study (divided over the EU participant group and non-EU participant group).

\section{EU participants}

Agricultural Economics Research Institute (LEI)

AgroBiolnstitute

College of Agriculture Food and Rural Enterprise (CAFRE)

Confederation of the Food and Drink Industries of the EU (CIAA)

Dutch Food and Consumer Product Safety Authority (VWA)

Dutch Ministry of Agriculture, Nature and Food Quality (LNV)

European Food Safety Authority (EFSA)

ESRC - Centre for Genomics in Society

EuroCommerce

EuroCOOP

European Association of Craft, Small and Medium-sized

Enterprises (UEAPME)

European Commission - DG Enterprise and Industry

European Commission - DG Research

European commission - DG SANCO

European Food Information Council

Finnish Farmers' and Forest Owners' Union (MTK)

International Life Sciences Institute (ILSI Europe)

Juelich Centre

Karolinska Institutet

Ministry of Agriculture of Latvia

Nestlé

Norwegian National Committee for Research Ethics in Science and Technology (NENT)

Ospedale Luigi Sacco University

Research Institute Organic Agriculture (FiBL)

Royal London Hospital

Unilever

University College Dublin

University of Reading

Wageningen University

Agricultural Economics Research Institute

AgroBioInstitute

College of Agriculture Food and Rural Enterprise (CAFRE)

Non-EU participants

Bayer CropScience

Canadian Food Inspection Agency

Centre for Food Safety (Hong Kong)

Food and Agriculture Organization of the United Nations (FAO)

Food Standards Australia New Zealand

Ibaraki Prefectural University of Health Science

Joint FAO/IAEA Division (AGE)

National Food Research Institute - Slovakia Republic

New Zealand Institute for Crop \& Food Research Limited

Organisation for Economic Co-Operation and Development

(OECD)

PRIMAFF

South Africa National Consumers Union

Universidad de Chile

University of Ottawa

World Health Organisation (WHO)

Zhejiang University 


\section{References}

Arrow, K.J., Cropper, M.L., Eads, G.C., Hahn, R.W., Lave, L.B., Noll, R.G., Portney, P.R., Russell, M., Schmalensee, R., Smith, V.K., Stavins, R.N., 1997. Is there a role for benefit-cost analysis in environmental, health, and safety regulation? Environment and Development Economics 2 (2), 195-221.

Avery, A.J., Savelyich, B.S.P., Sheikh, A., Cantrill, J., Morris, C.J., Fernando, B., Bainbridge, M., Horsfield, P., Teasdale, S., 2005. Identifying and establishing consensus on the most important safety features of GP computer systems: eDelphi study. Informatics in Primary Care 13 (1), 3-11.

Berg, L., 2004. Trust in food in the age of mad cow disease: a comparative study of consumers' evaluation of food safety in Belgium, Britain and Norway. Appetite 42 (1), 21-32.

Branen, A.L., Davidson, P.M., Salminen, S., Thorngate, J.H., 2002. Food Additives, second ed. Marcel Dekker, New York/Basel.

Byrne, D., 2002. EFSA: excellence, integrity and openness. In: Inaugural Meeting of the Management Board of the European Food Safety Authority, Brussels, 18 September 2002.

Childs, N.M., 1998. Public policy approaches to establishing health claims for food labels: an international comparison. British Food Journal 100 (4), 191-200.

Cope, S., Frewer, L.J., Renn, O., Dreyer, M., in press. Potential methods and approaches to assess social impacts associated with food safety issues. Food Control.

de Blok, B.M.J., Vlieg-Boerstra, B.J., Oude Elberink, J.N.G., Duiverman, E.J., DunnGalvin, A., Hourihane, J.O'B., Cornelisse-Vermaat, J.R., Frewer, L., Mills, C., 2007. A framework for measuring the social impact of food allergy across Europe: a EuroPrevall state of the art paper. Allergy 62 (7), 733-737.

De Jonge, J., van Trijp, J.C.M., Renes, R.J., Frewer, L.J., 2007. Understanding consumer confidence in the safety of food; it is two dimensional structure and determinants. Risk Analysis 27 (3), 729-740.

De Marchi, B., Ravetz, J.R., 1999. Risk management and governance: a post-normal science approach. Futures 31 (7), 743-757.

Dreyer, M., Renn, O., Borkhart, K., Ortleb, J., 2006. Institutional re-arrangements in European food safety governance: a comparative analysis. SAFE FOODS Project, WP5.

Dreyer, M., Renn, O., Cope, S., Frewer, L.J., in press. Including social impact assessment in food safety governance. Food Control.

Eiser, J.R., Miles, S., Frewer, L.J., 2002. Trust, perceived risk, and attitudes toward food technologies. Journal of Applied Social Psychology 32 (11), 2423-2433.

FAO/WHO, 1995. Application of risk analysis to food standards issues. Joint FAO/ WHO Expert Consultation. WHO, Geneva, Switzerland.

Fischer, A.R.H., Frewer, L.J., in press. Consumer familiarity with foods and the perception of risks and benefits. Food Quality and Preference.

French, S., Maule, A.J., Mythen, G., 2005. Soft modelling in risk communication and management: examples in handling food risk. Journal of the Operational Research Society 56 (8), 879-888.

Frewer, L.J., Howard, C., Hedderley, D., Shepherd, R., 1996. What determines trust in information about food-related risks? Underlying psychological constructs. Risk Analysis 16 (4), 473-486.

Frewer, L.J., Lassen, J., Kettlitz, B., Scholderer, J., Beekman, V., Berdal, K.G., 2004. Societal aspects of genetically modified foods. Food and Chemical Toxicology 42 (7), 1181-1193.

Gochfeld, M., Burger, J., 2005. Good fish/bad fish: a composite benefit-risk by dose curve. Neurotoxicology 26 (4), 511-520.

Green, C.G., Khan, M.A., Badinelli, R., 1993. Use of the Delphi research technique to test a decision model in foodservice systems: a case study in food production. Journal of the American Dietetic Association 93 (11), 1307-1309.

Guard-Petter, J., 2001. The chicken, the egg and Salmonella enteritidis. Environmental Microbiology 3 (7), 421-430.

Halal, W.E., Kull, M.D., Leffmann, A., 1998. The George Washington University forecast of emerging technologies a continuous assessment of the technology revolution. Technological Forecasting and Social Change 59 (1), 89-110.

Henson, S., 1997. Estimating the incidence of food-borne Salmonella and the effectiveness of alternative control measures using the Delphi method. International Journal of Food Microbiology 35 (3), 195-204.

Houghton, J.R., Rowe, G., Frewer, L.J., van Kleef, E., Chryssochoidis, G., Kehagia, O. Korzen-Bohr, S., Lassen, J., Pfenning, U., Strada, A., 2008. The quality of food risk management in Europe: perspectives and priorities. Food Policy 33 (1), 13-26.
Houghton, J.R., van Kleef, E., Rowe, G., Frewer, L.J., 2006. Consumer perceptions of the effectiveness of food risk management practices: a cross-cultural study. Health, Risk \& Society 8 (2), 165-183.

Janis, I., 1972. Victims of Groupthink. Houghton Mifflin, Boston.

König A., Kuiper, H.A., Marvin, H.J.P., Boon, P.E., Busk, L., Cnudde, F.C., Cope, S Davies, H.V., Dreyer, M., Frewer, L.J., Kaiser, M., Kleter, G.A., Knudsen, I., Pascal, G., Prandini, A., Renn, O., Smith, M., Traill, B.W., Van Der Voet, H., Van Trijp, H., Vos, E., Wentholt, M.T.A., submitted for publication. The SAFE FOODS framework for improved risk analysis of foods.

Levenson, C.W., Axelrad, D.M., 2006. Too much of a good thing? Update on fish consumption and mercury exposure. Nutrition Review 64 (3), 139-145.

Linstone, H.A., Turoff, M., 1975. The Delphi Method: Techniques and Applications. Addison-Wesley, London.

Medeiros, L.C., Kendall, P., Hillers, V., Chen, G., Dimascola, S., 2001. Identification and classification of consumer food-handling behaviors for food safety education. Journal of the American Dietetic Association 101 (11), 1326-1339.

Menrad, K., 1999. Future impacts of biotechnology on agriculture and food processing. Outlook on Agriculture 28 (3), 155-161.

Millstone, E., van Zwanenberg, P., 2000. A crisis of trust: for science, scientists or for institutions? Nature Medicine 6 (12), 1307-1308.

Padel, S., Midmore, P., 2005. The development of the European market for organic products: insights from a Delphi study. British Food Journal 107 (8), 626-646.

Ramsaran, H., Chen, J., Brunke, B., Hill, A., Griffiths, M.W., 1998. Survival of bioluminescent Listeria monocytogenes and Escherichia coli 0157:H7 in soft cheeses. Journal of Dairy Science 81 (7), 1810-1817.

Reilly, J., 1999. 'Just another food scare?' public understanding and the BSE crisis. In: Philo, G. (Ed.), Message Received: Glasgow Media Group Research, 1993-1998. Longman, New York, pp. 128-145.

Rowe, G., 2007. Public engagement in food policy. In: Frewer, L.J., van Trijp, J.C.M. (Eds.), Understanding Consumers of Food Products. Woodhead Publishing Ltd., Cambridge, pp. 592-609.

Rowe, G., Wright, G., 1996. The impact of task characteristics on the performance of structured group forecasting techniques. International Journal of Forecasting 12 (1), 73-89.

Rowe, G., Wright, G., 1999. The Delphi technique as a forecasting tool: issues and analysis. International Journal of Forecasting 15 (4), 353-375.

Rowe, G., Wright, G., 2001. Expert opinions in forecasting: role of the Delphi technique. In: Armstrong, S. (Ed.), Principles of Forecasting: A Handbook for Researchers and Practitioners. Kluwer Academic Publishers, Norwell, MA, pp. $125-144$.

Schneider, E.P., Dickert, K.J., 1993. Health costs and benefits of fungicide use in agriculture: a literature review. Journal of Agromedicine (1), 19-37.

Smith, A.P., Young, J.A., Gibson, J., 1999. How now, mad-cow? Consumer confidence and source credibility during the 1996 BSE scare. European Journal of Marketing 33 (11/12), 1107-1122.

Steiner, I.D., 1972. Group Process and Productivity. Academic Press, New York

Tuttle, J., Gomez, T., Doyle, M.P., Wells, J.G., Zhao, T., Tauxe, R.V., Griffin, P.M., 1999 Lessons from a large outbreak of Escherichia coli 0157-H7 infections: insights into the infectious dose and method of widespread contamination of hamburger patties. Epidemiology and Infection 122 (2), 185192.

Van Kleef, E., Houghton, J.R., Krystallis, A., Pfenning, U., Rowe, G., van Dijk, H., van der Lans, I.A., Frewer, L.J., 2007. Consumer evaluations of food risk management quality in Europe. Risk Analysis 27 (6), 1565-1580.

Verbeke, W., 2001. Beliefs, attitude and behaviour towards fresh meat revisited after the Belgian dioxin crisis. Food Quality and Preference 12 (8), 489498.

Vos, E., 2004. Overcoming the crisis of confidence: risk regulation in an enlarged European Union. Inaugural lecture, 23 January 2004, University of Maastricht.

Walls, J., Rowe, G., Frewer, L.J., in press. Stakeholder engagement in food risk management: evaluation of an iterated workshop approach. Public Understanding of Science.

WHO, 2004. Food and health in Europe: a New Basis for Action. WHO Regiona Publications, European Series, No 96.

Wilson, D.A.H., 2002. Animal psychology and ethology in Britain and the emergence of professional concern for the concept of ethical cost. Studies in History and Philosophy of Science Part C: Studies in History and Philosophy of Biological and Biomedical Sciences 34 (1), 201 (235-261). 